\title{
Microstructural Characterization of Extrusion Welds in 6xxx Aluminum alloys
}

\author{
X. Ren, J. L. Zhang, J. P. Li \\ National Engineering Research Center For Plastic Working Of Aluminium Alloys, SHANDONG \\ NANSHAN ALUMINIUM CO.,LTD., Longkou 265713 China \\ Beijing Nanshan Institute of Aeronautical Materials, Beijing 100048 China \\ J. Liu, H. H. Zhang, X. R. Wang, \\ National Engineering Research Center For Plastic Working Of Aluminium Alloys, SHANDONG \\ NANSHAN ALUMINIUM CO.,LTD., Longkou 265713 China
}

\begin{abstract}
Keywords: Microstructural Characterization, Extrusion Welds, Aluminum alloys
ABSTRACT: In this study, the microstructure of extrusion welds (including charge welds and seam welds) in a curtain wall hollow profile made of 6063 alloy is investigated using both Optical and Scanning Electron Microscopy (OM \& SEM, respectively). The grain size and the morphology, size and distribution of particles were different in seam weld, charge weld and matrix, due to variations in thermal deformation and recrystallization. Meanwhile, the relation of microstructural to the anodized streaks is also discussed. Considering both the practical extrusion process and reported literatures, the most important factors among the numerous extrusion parameters are analyzed.
\end{abstract}

\section{Introduction}

Compared with other manufacturing methods in aluminum industry, extrusions often provide a low cost method to produce profiles of complex shapes with high geometric tolerances in long lengths. Aluminum alloy extrusions are widely used in many markets including transportation (e.g., automotive structural supports, small to large truck, rail power systems, portable storage containers and railcars), construction(doors, windows, ladders), marine(offshore structures), heat exchanger tubes, and electronics(mobile phone and computer bodies) [1]. However, the largest volume of extruded products is used in construction industry.

The heat treatable Al-Mg-Si series alloys are usually used for producing extrusions because of their excellent extrudability and capability of achieving good mechanical strength. A curtain wall construction profile, extruded from 6063 alloy, is investigated in the present work. For decorative building materials, surface appearance is as important as mechanical properties. The extrusion welds can become visible by naked eye after etching and anodizing treatments. The obvious surface condition along the weld can cause customers to reject these products for "low quality". Therefore, die designers mostly arrange the steel bridges where welding occurs in the extrusion to non-decorative positions. But for some profiles with much wider exposed surfaces, the extrusion welds are located on the decorative surface and can become visible after etching and anodizing treatment.

The extrusion welds are of two types: seam and charge welds. Seam welds are longitudinal (in the extrusion direction) and charge welds are more in the transverse (normal to the extrusion direction) [2]. Seam welds are formed as the hot aluminum alloy fills the holes of the porthole die, flows around the steel support structure, comes back together with aluminum flowing around the other side of the support structure and metallurgically welds just before going through the die. A charge weld occurs when the front end of a new billet is pressed against the accumulated residual metal in the die from the previous billet and metallurgically welds under the extreme pressures and high temperatures of extruding through the port holes and die opening.

Seam welds only occur in hollow profiles extruded by porthole dies. By contrast, charge welds can appear in both hollow and solid extrusion profiles. For hollow profiles, the seam welds exit along the entire length of the extrusions. The charge welds are mostly visible near the front of the extrusion but can angle back into the extrusion near its surface and thus vary along its length. The variation-ofstructure condition can still be retained in the extrusion even after a length is cut off from the front end of the extrusion. Figure 1, shows the coexistence of seam and charge welds. In the longitudinal direction, the seam weld is centered between the charge welds, the latter having a parabolic shape. The prominent difference between seam and charge welds is observed in the forward end of the extrusions, as shown in A-A section of the Figure 1. It becomes more difficult to distinguish between them [2] as the extrusion process continues along the profile's length, which is demonstrated in B-B 
and C-C sections. The charge welds are located close to the inner and outer surfaces of the profile [3].

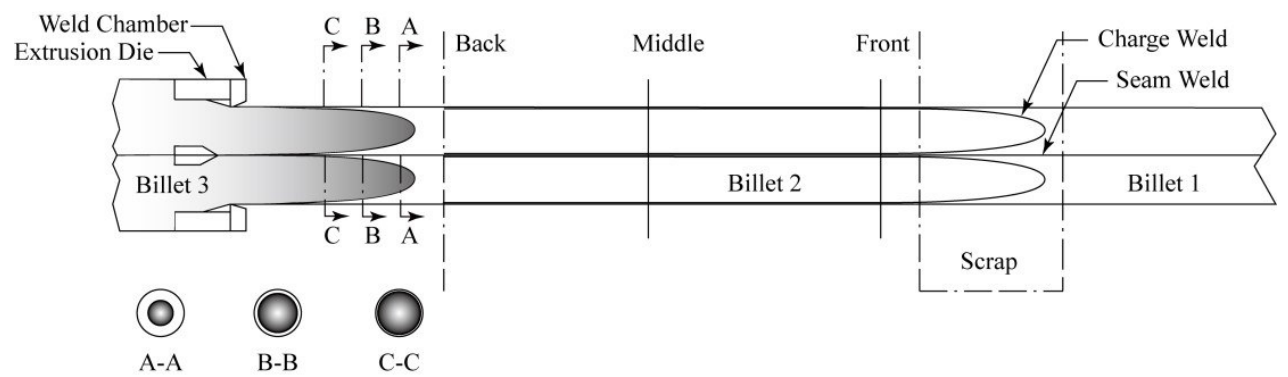

Figure 1 The extrusion welding process showing the seam weld and charge weld in a longitudinal direction [2]

The performance inspection and structural characterization of extrusion welds made in porthole dies have been studied by many investigators. Pietro et al [4], Donati and Tomesani [5] and Ceretti et al [6] investigated the die design solutions for the production of extruded sections without forming longitudinal weld streaks in architecturally finished parts. Loukus et al [7], Engelhardt et al [8] and Oosterkamp et al [9] studied the mechanical properties of the welded regions in detail, and revealed that the welded region is less ductile than the regions away from the welds. Loukus et al [7], Oosterkamp et al [9], Zhang et al [10] and Bingöl et al [11] also researched the structure of extrusion welds. In the numerous studies, many researchers confused the difference between the seam and charge welding zones. Zhang et al [10] investigated the oxide distribution and microstructure in seam and charge welding zones by means of finite element method, scanning electron microscopy and optical microscopy. It was observed that the microstructure differences between seam and charge welding zones. The study used pure aluminum for the first billet and then a 6061 alloy billet making the difference between seam weld and charge weld clearly visible. However, in the commercial production of a multiple-billet extrusion campaign of the same alloy, it is quite difficult to make a distinction between seam weld and charge weld.

In this current study, a commercial curtain wall profile using 6063 alloy is examined. The seam weld was distinguished from the charge weld using a mechanical marking method. The technique allowed the investigators to locate and study the microstructure of seam weld, charge weld and matrix using OM and SEM.

\section{Experiment Procedures}

A curtain wall profile with extrusion welds was obtained from SHANDONG NANSHAN ALUMINUM CO., LTD. It was extruded in the 35MN MEIUREY aluminum profile press from 6063 alloy. Table 1 lists the nominal chemical composition of AA6063 alloy. Standard commercial extrusion temperatures, pressures and speeds were used in producing the extrusion studied in this report.

Table 1 Alloying Element Limits for Chemical Composition of AA6063 alloy

\begin{tabular}{ccccccccccc}
\hline \multirow{2}{*}{6063} & \multicolumn{10}{c}{ Composition in weight \% } \\
\cline { 2 - 12 } & $\mathrm{Si}$ & $\mathrm{Fe}$ & $\mathrm{Cu}$ & $\mathrm{Mn}$ & $\mathrm{Mg}$ & $\mathrm{Cr}$ & $\mathrm{Zn}$ & $\mathrm{Ti}$ & Other & $\mathrm{Al}$ \\
\hline Min & 0.20 & & \multicolumn{1}{c}{0.45} \\
$\mathrm{Max}$ & 0.60 & 0.35 & 0.10 & 0.10 & 0.90 & 0.10 & 0.10 & 0.10 & 0.05 & Bal. \\
\hline
\end{tabular}

As shown in Figure 2, $12 \times 15 \times 3 \mathrm{~mm}$ size specimens containing extrusion welds were cut from the profile using a wire-electrode cutting machine. The specimens were metallographically prepared to a $1.5 \mu \mathrm{m}$ diamond polish, and then etched to better expose the microstructure and grain structure. Keller's and Barker's reagents were used to obtain the general macrostructure and the grain size respectively. The microstructural observation of the transverse and longitudinal sections was carried out with a ZEISS (Axio Imager M2m) light optic microscope. Specimens without etching were also prepared to observe the distribution of the intermetallic particles in seam weld, charge weld and matrix regions using Scanning Electron Microscopy (SEM-ZEISS EVO 18). Energy Dispersive Spectroscopy (EDS) was utilized to determine the approximate chemical composition of the intermetallic particles. Due to the extrusion welds being indistinguishable in the specimen without etching, several 
microscopic indentations were placed on the longitudinal section of the sample using a microhardness tester, as the schematic diagram shows in Figure 3.

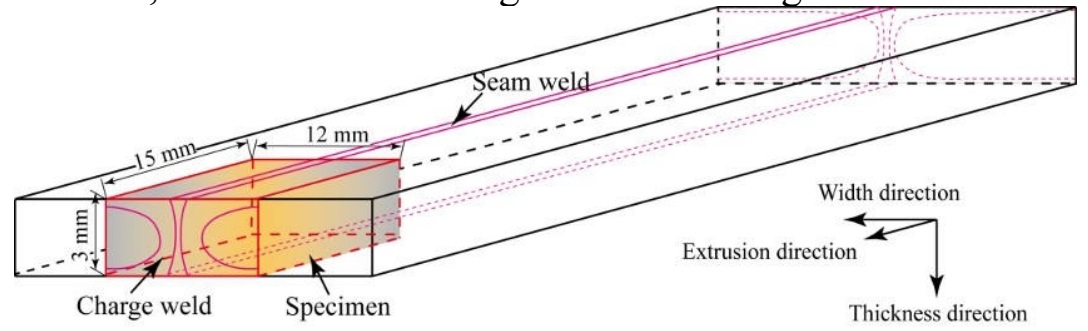

Figure 2 Schematic diagram for preparing experimental samples in this study

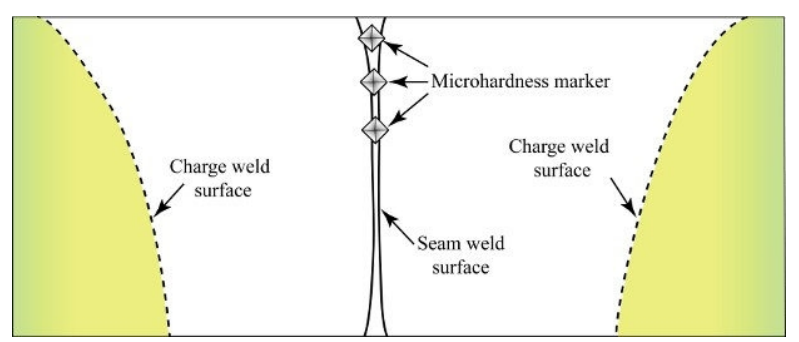

Figure 3 Schematic map of micro-hardness marker on the longitudinal section

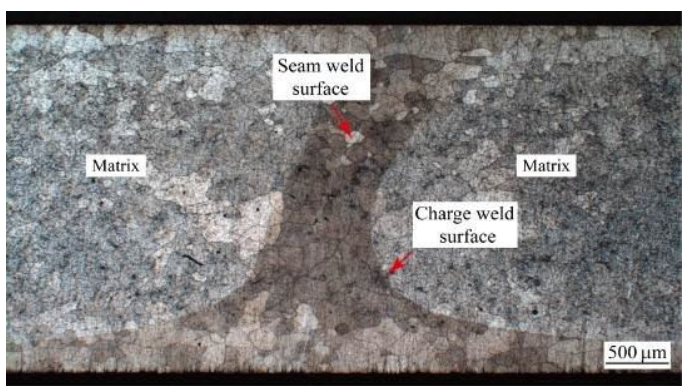

Figure 4 General structure of seam weld and charge weld after immersion in Keller's Etch for 30 seconds

\section{Experiment results}

The variation of metal flow in and around the extrusion welds was highlighted by using Keller's solution, Figure 4. The charge welds with a "tongue" shape were visible beside the seam weld in the extrusion's crosssection.

To better highlight the grain structure, the specimens were etched in Barker's reagent and examined with polarized light plus a sensitive tint filter, Figure 5 and 6 . In the two figures, letters A and $\mathrm{C}$ represent the matrix away from the extrusion weld, and $\mathrm{B}$ represents the region that includes both the seam weld and charge weld. The seam welding region is unrecognizable because of its narrow width, while the charge welding zones were observed as coarse equiaxed grains. Finer recrystallized grains were formed in the matrix, which can be seen in A1, C1 and A2, C2 regions in Figure 5 and 6, respectively.
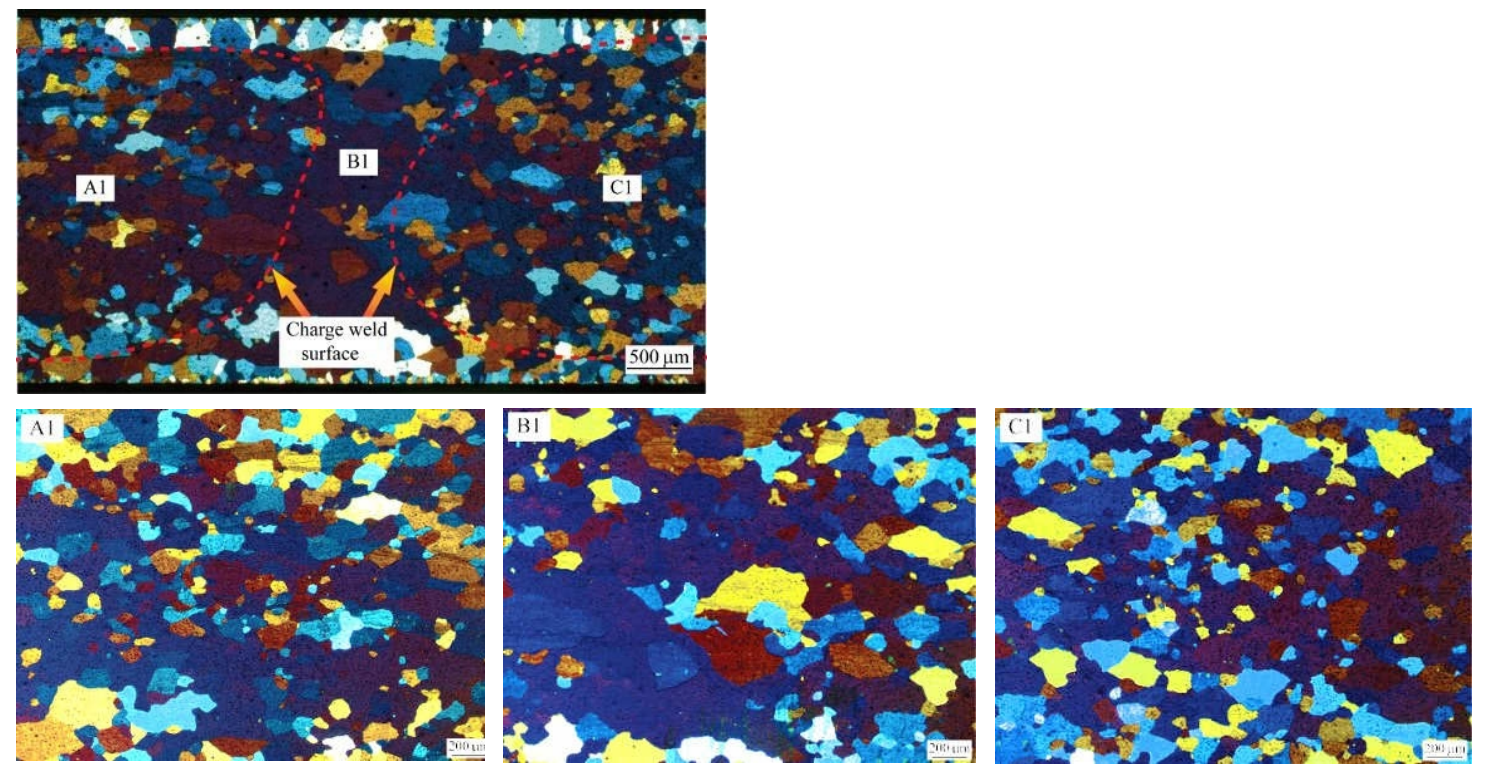

Figure 5 Grain size differences in the transverse section of the profile: (A1\&C1) matrix; (B1) extrusion weld region 

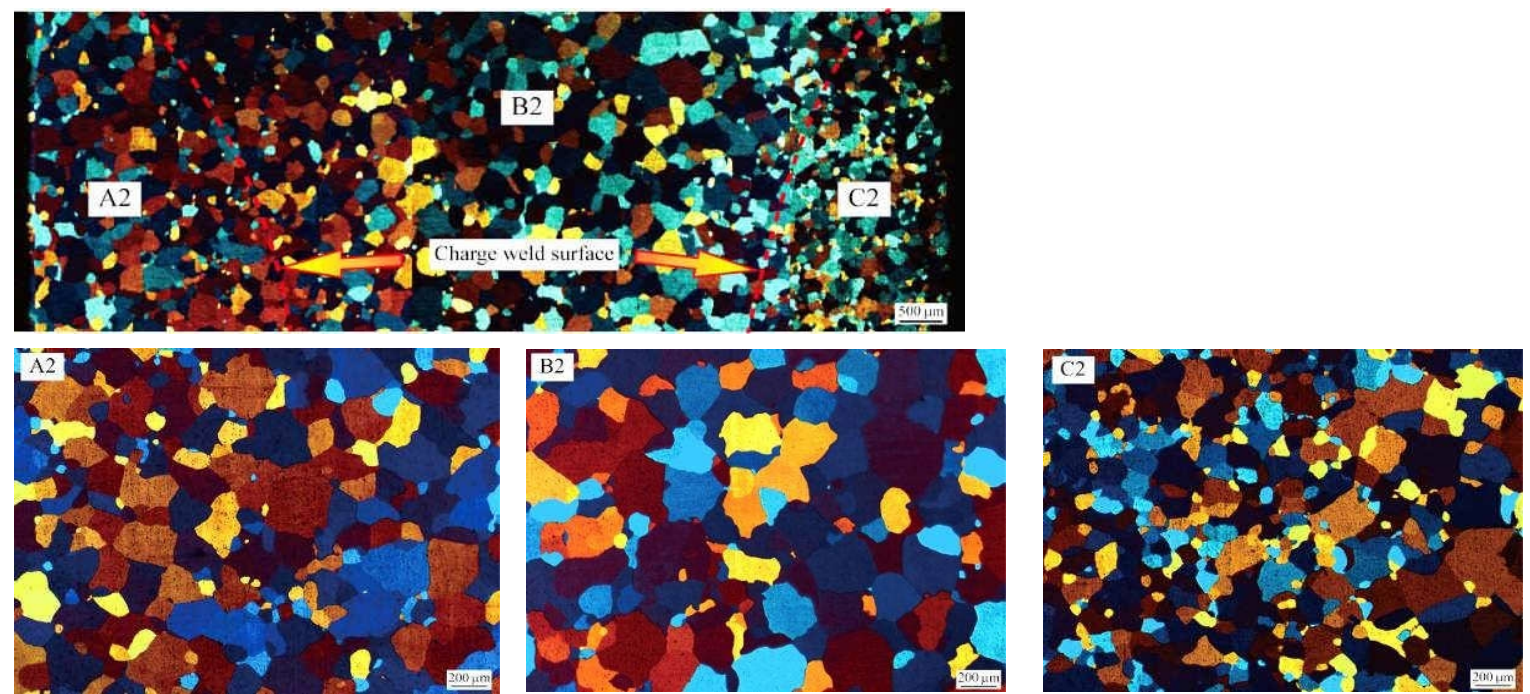

Figure 6 Grain size differences in the longitudinal section of the profile: (A2\&C2) matrix; (B2) extrusion weld region

The distribution of intermetallic particles in and near the weld zones were not easily revealed by polarized light OM observations. Therefore, polished samples without etching were observed using SEM in Back Scattered emission Mode (BSM). Micro hardness indentations in Figure 7a represent the seam weld region. The variation in the distribution of intermetallic particles in the seam weld, charge weld and matrix regions are displayed in Figure 7b-d. The region between the red dotted lines illustrates the seam weld location. The intermetallic particles between these lines are much less dense and smaller than in the charge weld region (Fig.7c) or the coarsest structure in the matrix (Fig.7d). The compositions of two particles detected by EDS are shown in Figure 8. These represented all of the light colored particles in the SEM micrographs. It is well known in the industry that the $\mathrm{Fe} / \mathrm{Si}$ containing intermetallics in properly homogenized 6063 alloy extrusions are mostly $\alpha-\mathrm{Al}_{12} \mathrm{Fe}_{3} \mathrm{Si}_{2}$ phase.
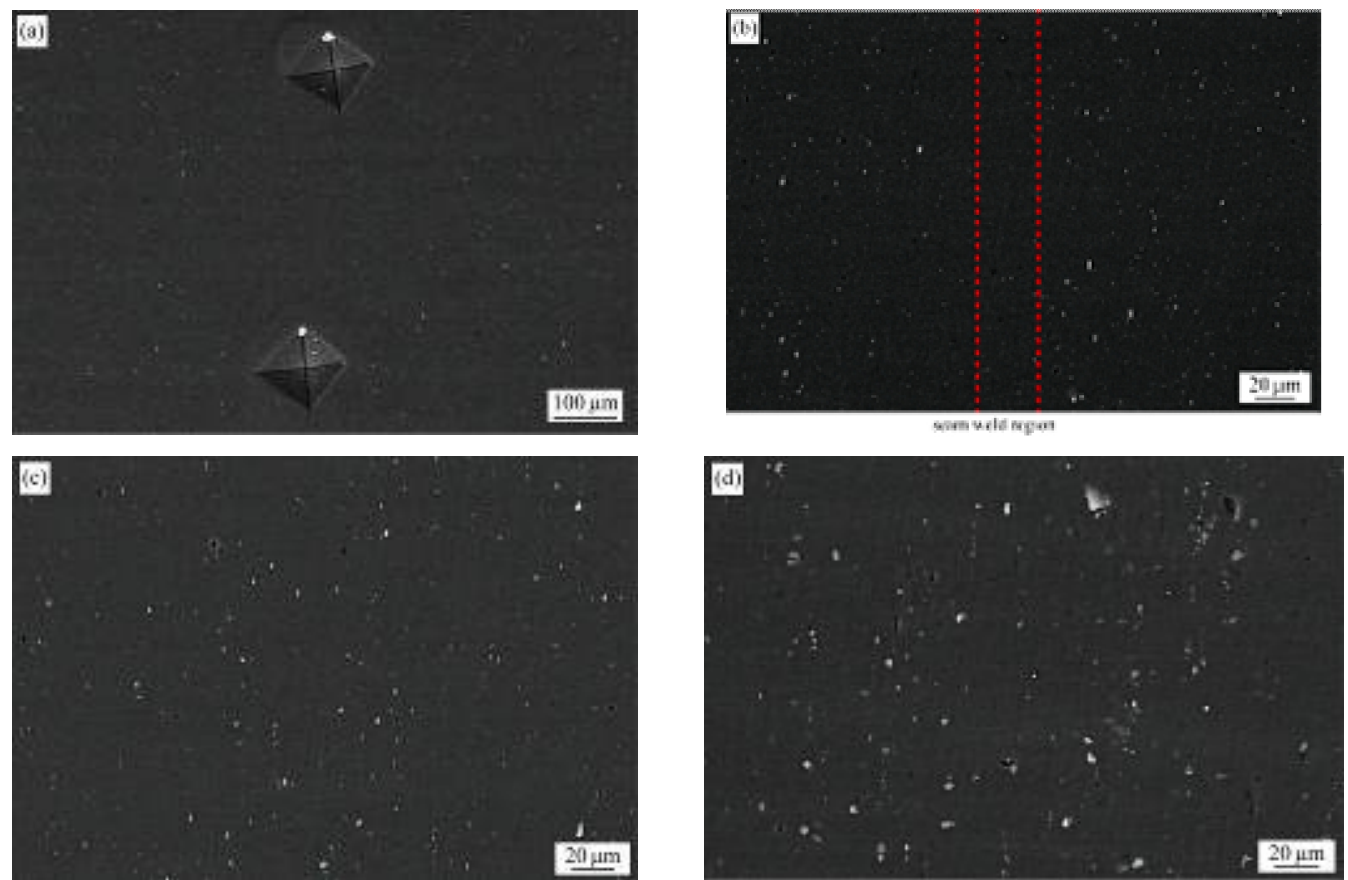

Figure 7 The micro-hardness indications in the seam weld region (a) and the difference of intermetallic particles in (b) seam weld region, (c) charge weld zone \& (d) matrix 


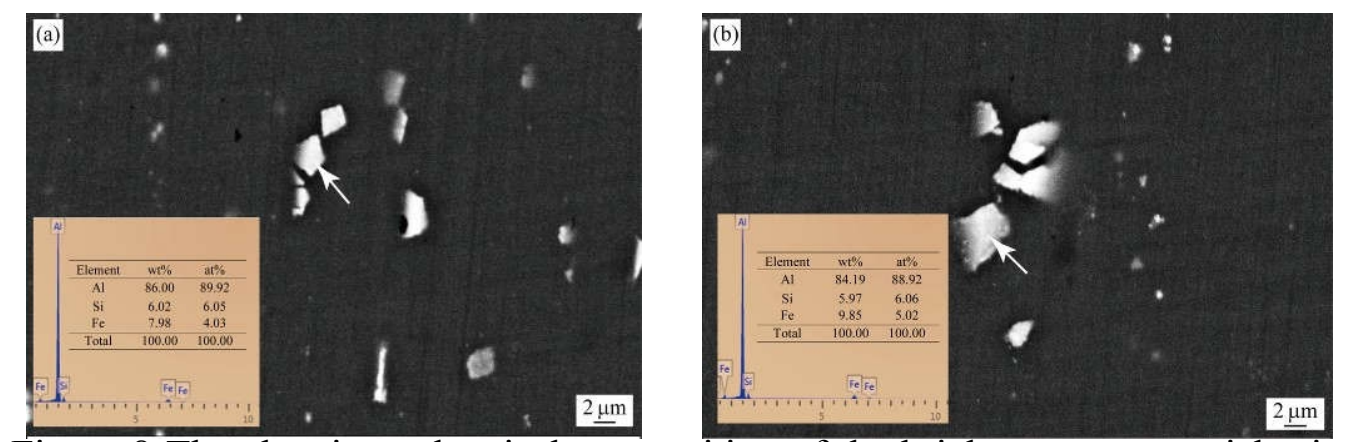

Figure 8 The chemistry chemical composition of the bright contrast particles in the sample are shown in the EDS data tables to the right of the SEM micrographs

\section{Discussion}

\section{General structure}

In the production of hollow profiles, the seam welds are formed when the hot aluminum alloy splits around the steel bridges to fill several ports and then rewelds on the other side of the bridges before exiting the die. The number of seam welds in the profiles equals the number of bridges. The charge welds are produced in the multi-billet extrusion process where the front end of the next billet welds to the back end of the previous billet's remnant that remains in the die. Relatively very thin layers of previous billets can extrude through the die as essentially a "cladding" with decreasing thickness from front to back of each extrusion. The more billets extruded, the more layers potentially will accumulate in the porthole die and flow into the profile just subsurface. The contacting surfaces of the previous and the new billets will flow forward with highest speed in the middle of the die cavities. Therefore, the charge welds will be convex (or "tongue") shape at the beginning of the extrusion and then constantly change its orientation until it becomes essentially longitudinal to the extrusion direction [2].

\section{Grain size}

According to the shearing mechanism [2], the extrusion metal of welding zones is subjected to a very heavy shear deformation during the inhomogeneous deformation of extrusion. The severe friction in the welding regions resulted in much higher temperature than in the matrix (away from the welds). However, the seam welding zone was unrecognizable when etched for grain structure, because the width was too narrow. It was about one third of the average grain size. The charge welding zones in the B1 and B2 regions in transverse and longitudinal sections, respectively (Fig.5 and 6). As mentioned above, the microstructure in this region consisted of relatively coarse equiaxed grains. This indicated the relatively narrow weld region was hotter than the surrounding matrix and dynamically recovered somewhat while still in the die. After exiting the die this region had lower strain and thus recrystallized into coarser grains than the metal away from the welds (A1, C1 in transverse section (Fig.5) and A2, C2 in longitudinal section (Fig.6)).

\section{Size and distribution of intermetallic particles}

The 20-30 micron wide band adjacent to the seam weld (bracketed by red dashed lines in Fig.7b) shows much fewer and smaller intermetallic particles compared to those in charge weld zone (Fig.7c) or those in the matrix (Fig.7d). The range in size and distribution of intermetallic particles between the welding regions and the matrix could be also due to the inhomogeneous deformation of extrusion. According to the composition determined by EDS, the bright particles are all Fe/Si-containing intermetallics, Figure 8 . Note these particles appear very brittle. In the seam weld region, the metal bears severe shearing forces and the intermetallic particles significantly break up. For the relatively mild force, the particles in the charge weld region are somewhat larger, while those in the matrix are coarsest due to even more subtle shear forces.

It is known in the industry that a proper homogenization of 6063 alloy billet will dissolve the ascast $\beta-\mathrm{Mg}_{2} \mathrm{Si}$ particles and transform in the solid state the $\beta-\mathrm{Al}_{9} \mathrm{Fe}_{2} \mathrm{Si}_{2}$ particles into $\alpha-\mathrm{Al}_{12} \mathrm{Fe}_{3} \mathrm{Si}_{2}$ particles. The strength of 6063 alloy is controlled by four key process steps: 1) the alloy's chemical composition where higher percentage of $\mathrm{Mg}$ and/or Si will allow for higher strength -T6 temper extrusions, 2) adequate homogenization and reheating of the billet to high enough temperature that essentially all $\beta-\mathrm{Mg}_{2} \mathrm{Si}$ phase particles dissolve into the aluminum matrix during the hot extrusion process, 3) adequate quenching to room temperature (cooling fast enough to hold the $\mathrm{Mg}$ and $\mathrm{Si}$ in solid solution) and then 4) heat treating to a relatively low temperature to precipitate the right distribution of nanometer size $\beta$ " particles that increase the strength to its designed level. Undissolved $\beta$ - 
$\mathrm{Mg}_{2} \mathrm{Si}$ phases in asextruded parts are adverse to the hardening effect. No visible $\beta-\mathrm{Mg}_{2} \mathrm{Si}$ phases were found larger than 0.5 microns in this extrusion. From the quasi-binary Al-Mg-Si alloy equilibrium phase diagram in Figure.9, the solid solubility line is about $440 \sim 460^{\circ} \mathrm{C}$ for conventional 6063 composition. In the actual production process, the exiting temperature was controlled at about $530^{\circ} \mathrm{C}$, which as predicted was high enough to dissolving the $\beta-\mathrm{Mg}_{2} \mathrm{Si}$ phases.

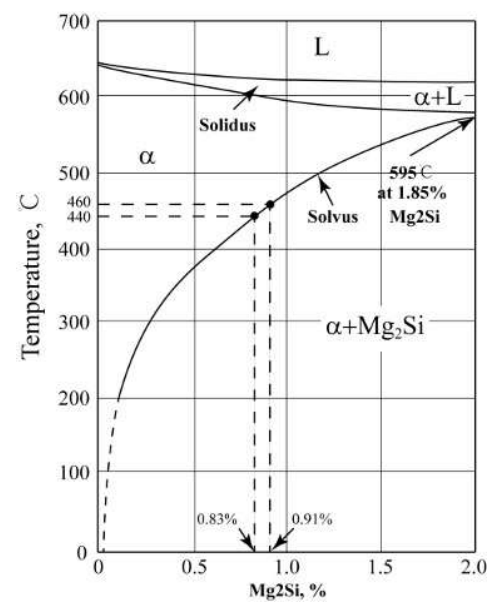

Figure 9 The quasi-binary Al-Mg-Si alloy equilibrium phase diagram

\section{Relation of microstructural to streaks}

The as-extruded curtain wall profiles are usually subjected to surface cleaning by deoxidizing with a chemical solution (a pseudo-etching process) and then anodizing. In the chemical cleaning process surface grain boundaries, being more chemically active, are attacked more than the matrix creating a microscopic roughening of the surface that causes some scattering of reflected light. As discussed earlier, the inhomogeneous distribution of Fe-containing intermetallic particles created variable "clarity" in the anodize layer because the particles are not anodized and also cause scattering of reflected light. Thus, the combination of the variable grain structure and distribution/size of the insoluble intermetallic particles caused variable light scattering patterns across the extrusion welds after anodizing that lead to the visible surface streaks $[12,13]$. The relatively few and small intermetallic particles combined with relatively coarse grain structure in the weld regions compared to the matrix resulted in reduced light scattering and consequently, brighter surface streaks.

\section{Key points for extrusion}

Anodized surface streaks like those examined in this report seem to be mostly due to the range of structures found in the weld regions. To ensure an acceptable hollow extrusion for surface critical products, key extrusion parameters must be controlled $[3,14-16]$. The mean stress on the aluminum in the welding chamber is directly related to the hydrostatic pressure in that chamber. Variability in this pressure can affect the weld quality and the occurrence of streaks[4]. Die design of the bridges and portholes is a key parameter in creating stress in the aluminum. Time to weld after the bridge before exiting the die is also important for good surface quality.

According to the effects of different extrusion parameters on seam welds, investigators Bingöl et al [11], Bingöl and Keskin [17] and Zhang et al [18] concluded the billet temperature and ram speed were the most influential parameters. The billets in high temperature or extruded with fast speed will reduce the welding time and also will result in less hydrostatic pressure in welding chamber. Accordingly, the most attention should be paid to the billet temperature and ram speed in practical production.

\section{Conclusion}

Microstructural investigation using OM and SEM performed on an anodized aluminum profile with surface streaks in line with extrusion welds revealed that:

1) Obviously differences in grain size were observed. The seam weld regions were not visible because of its narrow width and similar grain structure compared to the matrix. Coarser recrystallized grains were observed in charge welding zones compared with the matrix.

2) The differences of size, amount and distribution of the insoluble intermetallic particles between the seam weld, charge weld and matrix were very apparent. Relatively few and small intermetallic particles were observed in the seam weld region, while denser and larger particles are found in the matrix. 
3) Among the numerous factors, the billet temperature and the ram speed are probably the most influence parameters for controlling anodizing streaks in/near seam welds.

\section{Reference}

[1] Zhu, H. Couper, M. J. and Dahle, A. K. 2011. Effect of process variables on Mg-Si particles and extrudability of 6xxx series aluminum extrusions. Journal of Metals 63(11): 66-71.

[2] Valberg, H. 2002. Extrusion welding in aluminium extrusion. International Journal of Institute of Materials and Product Technology 17 (7): 497-556.

[3] Akaret, R. 1992. Extrusion welds-quality aspects are now center stage. Proceedings of the 5th International Aluminum Extrusion Technology Seminar Papers, Chicago, 1992.

[4] Fazzini, P. A. B. and Bellotti, S. 2008. How to obtain quality profiles surfaces. Aluminio E Leghe 6: 81-85.

[5] Donati, L. and Tomesani, L. 2005. The effect of die design on the production and seam weld quality of extruded aluminum profiles. Journal of Materials Processing Technology 164-165: 1025-1031.

[6] Ceretti, E. Fratini, L. Gagliardi, F. et al. 2009. A new approach to study material bonding in extrusion porthole dies. CIRP Annals-Manufacturing Technology 58: 259-262.

[7] Loukus, A. Subhash, G. and Imaninejad, M. 2004. Mechanical properties and microstructural characterization of extrusion welds in AA6082-T4. Journal of materials science 39: 6561-6569.

[8] Engelharde, M. Grittner, N. Bormann, D. et al. 2011. Microstructural weld seam characterisation in the as extruded condition for Al-Mg-Si-alloys. Materials Science and Engineering Technology 42(6): 531-541.

[9] Oosterkamp, A. Oosterkamp, L. D. and Nordeide, A. 2004. 'Kissing Bond' phenomena in solidstate welds of aluminum alloys. Welding Journal 83: 225-231.

[10] Zhang, X. Feng, D. Shi, X. et al. 2013. Oxide distribution and microstructure in welding zones from porthole die extrusion. Transactions of Nonferrous Metals Society of China 23(3): 765-772.

[11] Bingöl, S. Keskin, M. S. and Bozaci, A. 2007. Properties of seam welds produced with different extrusion parameters. Archives of Materials Science and Engineering 28(6): 365-368.

[12] Ma, Y. Zhou, X. Thompson, G. E. et al. 2013. Origin of streaks on anodised aluminium alloy extrusions. Transactions of the institute of metal finishing 91(1): 11-16.

[13] Zhu, H. Wei, T. Couper, M. J. et al. 2012. Effect of Fe-rich particles on the formation of die streaks on anodized aluminum extrusions. Journal of Metals 64(2): 337-345.

[14] Plate, M. and Piwnik, J. 2000. Theoretical and experimental analysis of seam weld formation in hot extrusion of aluminum alloys. Proceedings of 7 th International Aluminum Extrusion Technology Seminar, Chicago, 2000.

[15] Bourqui, B. Huber, A. Moulin, C. et al. 2002. Improved weld seam quality using 3D FEM simulation in correlation with practice. The first EAA extrusders division congress, Brescia Italy, 2002.

[16] Jo, H. H. Jeong, C. S. Lee, S. K. et al. 2003. Determination of welding pressure in the nonsteady-state porthole die extrusion of improved A17003 hollow section tubes. Journal of Materials Processing Technology 139(1-3): 428-433.

[17] Bingöl, S and Keskin, M. S. 2007. Effect of different extrusion temperature and speed on extrusion welds. Journal of achievements in materials and manufacturing engineering 23(2): 39-42.

[18] Zhang, C. S. Zhao, G. Q. Chen, Z. R. et al. 2012. Effect of extrusion stem speed on extrusion process for a hollow aluminum profile. Materials Science and Engineering B-Solid State Materials For Advanced Technology 177:1691-1697. 